\title{
Molecular investigation of Cryptosporidium and Giardia in pre- and post-weaned calves in Hubei Province, China
}

\author{
Yingying Fan ${ }^{1}$, Tao Wang ${ }^{2}$, Anson V. Koehler ${ }^{2}$, Min Hu${ }^{1}$ and Robin B. Gasser ${ }^{1,2^{*}}$
}

\begin{abstract}
Background: The protistan pathogens Cryptosporidium and Giardia can cause significant intestinal diseases in animals and humans. Cattle, particularly calves, carrying these protists can be significant reservoirs for human infections and disease. However, little is known about the genetic make-up of Cryptosporidium and Giardia populations in cattle and other ruminants in some regions of China.

Results: In the present study, PCR-based tools were used to genetically characterise these protists in faecal samples from a total of 339 pre- and post-weaned calves from four distinct locations in Hubei Province using markers in the large (LSU) or small (SSU) subunits of nuclear ribosomal RNA genes. Cryptosporidium andersoni, C. bovis, C. ryanae and Giardia duodenalis assemblage E were detected in $0.6 \%, 10.9 \%, 4.1 \%$ and $22.6 \%$ of calves, respectively.

Conclusions: This study is the first to report the prevalence of Cryptosporidium and Giardia in pre- and post-weaned calves in Hubei Province, and encourages large-scale molecular studies of animals and humans, in an effort to better understand the epidemiology of these enteric pathogens in China.
\end{abstract}

Keywords: Cryptosporidium, Giardia, Calves, PCR-based sequencing, Nuclear ribosomal RNA genes, China

\section{Background}

Cryptosporidium and Giardia are protistan pathogens that can cause intestinal diseases in animals and humans. Using molecular tools, numerous species/genotypes of Cryptosporidium [1] or species/assemblages of Giardia have been reported to infect humans [2]. However, based on current molecular data, Cryptosporidium hominis and C. parvum as well as Giardia duodenalis (syn. Giardia intestinalis, Giardia lamblia) assemblages $A$ and B are responsible for most (>99\%) human infections $[3,4]$. Of these parasites, $C$. hominis infection is considered to be acquired by anthroponotic transmission [5], whereas C. parvum and G. duodenalis (mainly assemblages $\mathrm{A}$ and $\mathrm{B}$ ) can be transmitted anthroponotically or zoonotically $[1,3,4]$.

Cattle, particularly calves, infected with these protists can represent a significant source of zoonotic infections

\footnotetext{
*Correspondence: robinbg@unimelb.edu.au

${ }^{1}$ State Key Laboratory of Agricultural Microbiology, College of Veterinary Medicine, Huazhong Agricultural University, Wuhan, Hubei 430070, China ${ }^{2}$ Department of Veterinary Biosciences, Melbourne Veterinary School, The University of Melbourne, Parkville, VIC, Australia
}

and disease $[4,6]$. Nevertheless, cattle can become infected with various species of Cryptosporidium or Giardia $[7,8]$. The species and genotypes or assemblages of these protists are known to vary among hosts of different age groups $[4,8]$ and geographical locations $[9,10]$, and new, previously undescribed genotypes of Cryptosporidium are being discovered in regions of the world not explored previously (cf. $[11,12])$. Therefore, establishing and comparing the specific and/or genotypic identity of these protists in animals and humans in geographical regions in which there is limited molecular epidemiological information are central to assessing their zoonotic potential.

In China, the diseases caused by Cryptosporidium and Giardia are not notifiable, but infected cattle are believed to serve as significant reservoirs for zoonotic infections [13]. Although there is a positive association between the density of domestic livestock, including cattle, and the prevalence of Cryptosporidium infection in humans in other countries (e.g. New Zealand) [14], there are presently relatively limited epidemiological data in some parts of China to support this observation. Most previous studies describing the genetic characterization 
of Cryptosporidium from calves have been conducted mainly in the northeast, northwest and central regions of China [13, 15-22]. Similarly, limited molecular data are available for Giardia of cattle in other regions, although G. duodenalis assemblages A and B have been identified in calves [16, 17, 23-26]. In Hubei Province, the only studies of Cryptosporidium and Giardia are those in diarrhoeic children [27] and goats [28].

The aim of the present study was to explore the species and genotypes of Cryptosporidium and assemblages of Giardia in calves on farms in Hubei Province, China, using markers in the large $(L S U)$ or small $(S S U)$ subunits of nuclear ribosomal RNA genes, and to assess the zoonotic potential of these parasites.

\section{Methods}

A total of 339 fresh faecal samples were collected (September to December 2016) from pre- and postweaned calves (1 to 12 weeks old) from one beef farm (i.e. Suizhou) and five dairy farms (i.e. Chezhan, Guangming, Meijiadun, Qiaoner and Yangzijiang) in the north, east and west regions of Hubei Province, China (Fig. 1). Faecal samples were collected rectally from individual calves and kept at $4{ }^{\circ} \mathrm{C}$ following sampling, and then frozen at $-20{ }^{\circ} \mathrm{C}$ for subsequent DNA isolation and molecular testing. Genomic DNA was extracted from $0.2 \mathrm{~g}$ of each faecal sample using the PowerSoil DNA Isolation Kit (MoBio, Carlsbad, USA), according to the manufacturer's protocol, and stored at $-20{ }^{\circ} \mathrm{C}$. This kit was used, as it is highly effective at removing components that are inhibitory to PCR [29-31]. Aliquots $(2 \mu \mathrm{l})$ of individual genomic
DNA samples were subjected to nested PCR-based amplification and sequencing, employing (individually) two distinct loci of nuclear ribosomal DNA in separate assays. For detection of Cryptosporidium, a portion of the large subunit of the nuclear ribosomal RNA gene ( $\mathrm{p} L S U c ; \sim 500 \mathrm{bp}$ ) was used [32], and further genotypic/subgenotypic classification was achieved by employing a portion of the small subunit of the nuclear ribosomal RNA gene (pSSUc; $590 \mathrm{bp)}$ [33]. For the specific and assemblage-based classification of Giardia, a portion of the SSU gene (pSSUg; 290 bp) was employed [34, 35] (Additional file 1: Table S1).

In brief, nested PCRs were carried out in $50 \mu \mathrm{l}$ using a standard reaction buffer, $2.0-3.0 \mathrm{mM}$ of $\mathrm{MgCl}_{2}$ (depending on the locus), $200 \mu \mathrm{M}$ of each dNTP, $50 \mathrm{pmol}$ of each primer and $1 \mathrm{U}$ of Taq polymerase (Mango DNA polymerase, Bioline, London, UK) using established cycling protocols (Additional file 1: Table S1). Except for the no-template controls, $2 \mu \mathrm{l}$ of genomic DNA were added to the primary PCR, from which $1 \mu \mathrm{l}$ was carried over to the secondary PCR. Known test-positive, testnegative and no-template controls were included in each PCR run.

All nested PCR products were detected by electrophoresis in ethidium bromide-stained (1.5\%) agarose gels before sequencing. For sequencing, aliquots $(5 \mu \mathrm{l})$ of individual amplicons (undigested) were treated with the enzymes Exo I and a thermosensitive alkaline phosphatase (FastAP, Thermofisher, Carlsbad, USA), according to the manufacturer's instructions, and then subjected to direct, automated sequencing (BigDye Terminator v.3.1

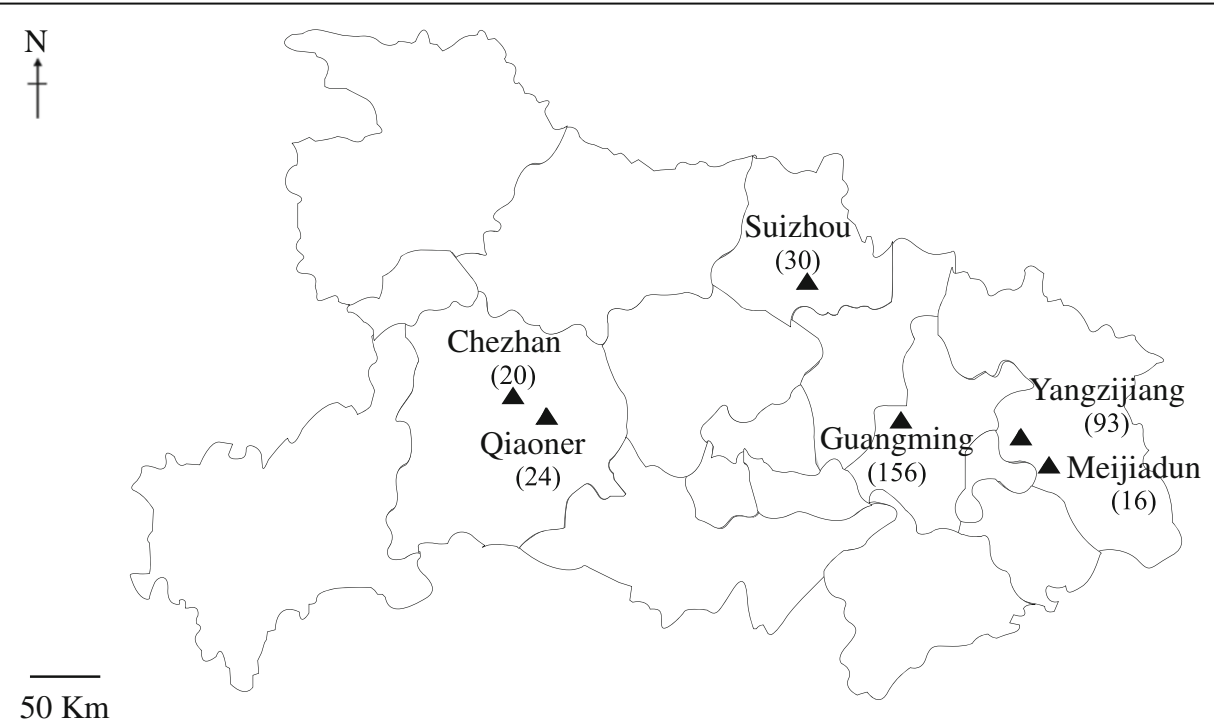

Fig. 1 Locations of the six farms in Hubei Province from which faecal samples (numbers in parentheses) were collected from pre- and postweaned calves and tested using PCR-based methods 
chemistry, Applied Biosystems, USA) in both directions using the same, internal primers as employed in PCR. The quality of each sequence was assessed based on the corresponding chromatogram, and sequences were matched to reference sequences from the GenBank database (listed in Additional file 2: Table S2) using the Basic Local Alignment Search Tool (BLAST; http:// www.ncbi.nlm.nih.gov/BLAST). Chi-square test was performed using SPSS Statistics 24 software (IBM, New York, USA).

\section{Results and discussion}

Using two separate PCR assays, the 339 individual faecal DNA samples from six farms from four counties/cities of Hubei Province were screened by PCR for the presence of Cryptosporidium spp. and Giardia duodenalis DNA, respectively. In total, $15.5 \%(n=53)$ and $22.6 \%$ $(n=77)$ faecal DNA samples were test-positive for Cryptosporidium and Giardia, respectively. Amplicons were sequenced, and the nucleotide sequences of Cryptosporidium and Giardia were deposited in the GenBank database under accession nos. MF196907-MF196910.

\section{Cryptosporidium}

Nested PCR-based sequencing of $\mathrm{p} L S U_{c}$ identified 53 samples that were test-positive for three Cryptosporidium species, including Cryptosporidium andersoni (0.6\%; 2 of 339) on two farms, and C. bovis (10.9\%; 37 of 339) and C. ryanae (4.1\%; 14 of 339 ) on five farms (Table 1 ). No mixed infections of these species were detected. Farm Meijiadun showed the highest overall infection rate $(31.3 \% ; 5$ of 16$)$ of Cryptosporidium, whereas farm Suizhou had the lowest rate $(3.3 \% ; 1$ of 30$)$. At least one Cryptosporidium species was detected on each farm. Cryptosporidium andersoni was found only on farms Qiaoner and Yangzijiang in two pre-weaned calves of 2 and 8 weeks of age, respectively. Cryptosporidium bovis was the major species on farms Yangzijiang, Meijiadun,
Qiaoner and Guangming, whereas C. ryanae was the dominant species on farms Chenzhan and Shuizhou (Table 1). There was no significant difference in Cryptosporidium prevalence between the beef farm and the dairy farms $\left(\chi^{2}=3.776, d f=1, P=0.0520\right)$.

Further analysis of pSSUc nucleotide sequence data showed that all sequences obtained were identical to reference sequences from GenBank (Additional file 2: Table $\mathrm{S} 2$ ). For $C$. andersoni, the sequence matched that recorded previously in Chongqing, China (calves; JX515549; unpublished); for C. bovis, three sequences matched those recorded in Qinghai Province (yak; KU052813; [36]), Sichuan Province (cattle; KT884495; unpublished) or Gansu Province (cattle; KP994913; [37]), China; for C. ryanae, two sequences matched those recorded previously in Gansu Province (cattle; KP994915; [37]) and Xinjiang Province (cattle; KP793013; [13]), China.

Cryptosporidium was found across both genders and all age groups of calves (Table 2). The results show that $8.2 \%$ (4 of 49 ) of male and $16.9 \%$ (49 of 290) of female calves were test-positive for Cryptosporidium, whereas $15.8 \%$ (42 of 265 ) of pre-weaned calves ( $\leq 8$ weeks) and $15.2 \%$ (11 of 74 ) of post-weaned calves (> 8 weeks) were identified as test-positive using the PCR-coupled sequencing approach for pSSUc (Table 2). The Chi-square test did not show any significant age- or gender-associated difference in the prevalence of Cryptosporidium infection $(P=0.838$ and 0.119 , respectively).

In China, increased attention is now being paid to cryptosporidiosis of livestock [38] due its clinical significance in young farm animals $[39,40]$ and potential to spread to humans. Previous studies have indicated that Cryptosporidium has a relatively wide distribution in cattle of different breeds and ages in China (reviewed by [38]). Since the initial detection of Cryptosporidium in diarrhoeic calves (prevalence: 45.2\%; 19 of 42) in Gansu Province [41], at least nine species of Cryptosporidium

Table 1 Occurrence of Cryptosporidium andersoni, Cryptosporidium bovis, Cryptosporidium ryanae and Giardia duodenalis in faecal samples from calves

\begin{tabular}{|c|c|c|c|c|c|c|}
\hline \multirow[t]{2}{*}{ Farm } & \multirow{2}{*}{$\begin{array}{l}\text { No. of } \\
\text { samples } \\
\text { tested }\end{array}$} & \multirow{2}{*}{$\begin{array}{l}\text { No. of samples } \\
\text { test-positive for } \\
\text { Cryptosporidium } \\
\text { spp. (\%) }\end{array}$} & \multicolumn{3}{|c|}{ Cryptosporidium species } & \multirow{2}{*}{$\begin{array}{l}\text { No. of } \\
\text { samples } \\
\text { test-positive } \\
\text { for Giardia } \\
\text { duodenalis (\%) }\end{array}$} \\
\hline & & & C. andersoni (\%) & C. bovis (\%) & C. ryanae (\%) & \\
\hline Suizhou (beef farm) & 30 & $1(3.3)$ & 0 & 0 & $1(3.3)$ & $7(23.3)$ \\
\hline Chezhan (dairy farm) & 20 & $5(25.0)$ & 0 & $1(5.0)$ & $4(20.0)$ & $12(60.0)$ \\
\hline Guangming (dairy farm) & 156 & $21(13.4)$ & 0 & $17(10.9)$ & $4(2.6)$ & $31(19.9)$ \\
\hline Meijiadun (dairy farm) & 16 & $5(31.2)$ & 0 & $5(31.3)$ & 0 & $3(18.8)$ \\
\hline Qiaoner (dairy farm) & 24 & $8(33.3)$ & $1(4.2)$ & $4(16.7)$ & $3(12.5)$ & $15(57.7)$ \\
\hline Yanzijiang (dairy farm) & 93 & $13(14.0)$ & $1(1.1)$ & $10(10.8)$ & $2(2.2)$ & $9(9.7)$ \\
\hline Total & 339 & $53(15.6)$ & $2(0.6)$ & $37(10.9)$ & $14(4.1)$ & $77(22.6)$ \\
\hline
\end{tabular}


Table 2 Age and gender distributions of Cryptosporidium spp. and Giardia duodenalis detected

\begin{tabular}{|c|c|c|c|c|c|c|}
\hline \multirow[t]{2}{*}{ Groups } & \multirow{2}{*}{$\begin{array}{l}\text { No. of } \\
\text { samples } \\
\text { tested }\end{array}$} & \multirow{2}{*}{$\begin{array}{l}\text { No. test-positive } \\
\text { for Cryptospori } \\
\text { dium spp. (\%) }\end{array}$} & \multicolumn{3}{|c|}{ Cryptosporidium spp. } & \multirow{2}{*}{$\begin{array}{l}\text { No. test-positive } \\
\text { for Giardia } \\
\text { duodenalis (\%) }\end{array}$} \\
\hline & & & C. andersoni (\%) & C. bovis (\%) & C. ryanae (\%) & \\
\hline \multicolumn{7}{|l|}{ Age (weeks) } \\
\hline Pre-weaned $(\leq 8)$ & 265 & $42(15.8)$ & $2(0.8)$ & $32(12.1)$ & $8(3.0)$ & $49(18.5)$ \\
\hline Post-weaned (> 8) & 74 & $11(14.9)$ & 0 & $5(6.8)$ & $6(8.1)$ & $28(37.8)$ \\
\hline \multicolumn{7}{|l|}{ Gender } \\
\hline Female & 290 & $49(16.9)$ & $2(0.7)$ & $34(11.7)$ & $13(4.5)$ & $66(22.8)$ \\
\hline Male & 49 & $4(8.2)$ & 0 & $3(6.1)$ & $1(2.0)$ & $11(22.4)$ \\
\hline
\end{tabular}

(i.e. C. andersoni [21], C. bovis [21], C. parvum [15], C. ryanae [18], C. ubiquitum [42], C. meleagridis [22], $C$. xiaoi [42], C. serpentis [43] and C. suis-like [44]) have been reported to date in cattle in 19 regions/provinces of China. Of these nine Cryptosporidium species, $C$. andersoni, $C$. bovis, C. parvum and C. ryanae were the predominant species in cattle in China [38]. Although $C$. parvum has been described previously as being more common in pre-weaned calves in numerous industrialised countries (e.g. Australia, Belgium, Japan and the USA [45-48] as well as some provinces/regions of China $[13,15-17])$, this was not the case in the present study, in which $C$. bovis was identified as being the predominant species in pre-weaned calves in Hubei Province. This finding is consistent with previous observations in the provinces Gansu [37], Henan [21], Helongjiang [22], Shaanxi [19] as well as in Shanghai [49]. Interestingly, the predominance of $C$. bovis in pre-weaned calves in China contrasts the situation in many other countries studied to date, where C. parvum tends to be the major agent detected [12]. Although this difference is challenging to explain, it might relate to different farming practices or simply that C. parvum is not widely established in livestock populations in some regions of China. Nonetheless, there may be seasonal differences in the presence of C. bovis and C. parvum. Indeed, Wang et al. [21] proposed that a seasonal shift might be responsible for the dominance of one or more Cryptosporidium species over others in pre-weaned calves. Future, large-scale temporal and spatial studies are required to test this hypothesis.

As seen in this study, C. andersoni, C. bovis and $C$. ryanae infections predominated in post-weaned calves, and are normally not associated with obvious clinical signs in the cattle [20, 50-52]. Nevertheless, such subclinical Cryptosporidium infections in cattle should not be neglected, as they may relate to chronic infections and can lead to decreased feed efficiency [53], impaired weight gain or weight loss [54] and milk production losses in dairy cows [52]. Given the expansion of the dairy industry in Hubei Province in China, further studies might explore the epidemiological significance of Cryptosporidium genotypes and the sub-structuring of Cryptosporidium populations in dairy cattle.

\section{Giardia}

Giardia DNA was detected in 77 faecal DNA samples. Similar to the results for Cryptosporidium, G. duodenalis was also found in calves on all six farms, with an average prevalence of $22.6 \%$ (Table 1). This number was consistent with previous studies of pre- and post-weaned calves from other cities/provinces of China [25, 55] as well as other countries (cf. [12]). The prevalence of Giardia varied from farm to farm in Hubei Province. Farm Chezhan had the highest percentage $(60.0 \% ; 12$ of 20) of infected calves, whereas farm Yangzijiang had the lowest percentage $(9.7 \% ; 9$ of 93$)$. There was no significant difference in the prevalence of $G$. duodenalis between the beef and dairy farms $\left(\chi^{2}=0.007, d f=1, P=0.933\right)$.

The age and gender distributions of G. duodenalis are shown in Table 2. Giardia was found across both sexes and all ages of calves (Table 2). The prevalences of $G$. duodenalis were $18.5 \%$ (49 of 265) and 37.8\% (28 of 74) in pre- and post-weaned calves, respectively, with a significant difference $\left(\chi^{2}=12.335, d f=1, P=0.0004\right)$ between the two groups. According to gender, the results showed that 22.4\% (11 of 49) of males and $22.8 \%$ (66 of 290) of females were test-positive for Giardia (Table 2). Nevertheless, there was no significant difference between the sexes $\left(\chi^{2}=0.002, d f=1, P=0.964\right)$.

The sequencing of amplicons from Giardia-positive samples $(n=77)$ revealed assemblage E. This assemblage has been commonly detected in previous studies of preand post-weaned calves from other regions in China, including Heilongjiang [23, 56], Shaanxi [25], Beijing [17], Henan [24], Liaoning [23], Jinling [23] and Shanghai [26], as well as other countries in the world [12]. The pSSUg sequences (292 bp) determined here were the same as those representing G. duodenalis assemblage E isolates from cattle from China (GenBank: KF843921 [24]), Brazil (GenBank: JF957620; unpublished data) and the USA (GenBank: JN375981 [57]); (GenBank: 
AY655701 [58]), as well as from deer (GenBank: KX259145; unpublished data) and takin (Budorcas taxicolor) (GenBank: KR048491 [59]) from China. Although current preliminary results of $G$. duodenalis from calves in Hubei Province suggest that the public health risk of zoonotic giardiasis is low here, previous longitudinal investigations of cattle giardiasis have indicated the possibility of the transient presence of zoonotic assemblages [60]. Although assemblage E, identified in the present study, had not been considered zoonotic [3, 4], some recent studies describe the occurrence of assemblage $E$ in humans in Queensland, Australia [61], Brazil [62] and Egypt [63-65], indicating that this assemblage can indeed be zoonotic. These recent findings could have important public implications in rural regions of countries such as China, where there is a close relationship between livestock and humans. Therefore, large-scale temporal and spatial studies should be conducted in the future to assess the molecular epidemiology and zoonotic potential of $G$. duodenalis assemblages in different age groups and breeds of cattle and in humans in agricultural regions of Hubei Province.

\section{Conclusions}

In the present study, for the first time, we have reported the prevalence of Cryptosporidium and Giardia in preand post-weaned calves in Hubei Province, China. Based on this 'snap shot' study, the prevalence of G. duodenalis was shown to be higher than that of Cryptosporidium spp. in calves in this province. Cryptosporidium bovis was identified as the predominant species in pre-weaned calves, consistent with findings from previous studies from other regions in China. In order to better understand the transmission of these enteric pathogens in China, further work is needed to evaluate the prevalence in large numbers of cattle from different age groups and breeds in different regions of China and at different time points throughout the year, and also to gain relevant information regarding Cryptosporidium and Giardia in humans and other animals in one of the fastest growing agricultural and economic regions in China (Hubei).

\section{Additional files}

Additional file 1: Table S1 Oligonucleotide primers and PCR protoco used in this study. (XLSX $37 \mathrm{~kb}$ )

Additional file 2: Table S2 Summary of information on the reference sequences from the GenBank database used in the present study. (XLSX $55 \mathrm{~kb}$ )

\section{Abbreviations}

pLSUc: a portion of the large subunit of the nuclear ribosomal RNA gene of Cryptosporidium; pSSUc: a portion of the small subunit of nuclear ribosomal RNA genes of Cryptosporidium; pSSUg: a portion of the small subunit of nuclear ribosomal RNA genes of Giardia

\section{Acknowledgements}

We thank all of the farmers for donating samples.

\section{Funding}

This project was supported by Huazhong Agricultural University Scientific \& Technological Self Innovation Foundation (Program no. 2015RC005) and partially funded by the Australian Research Council (ARC) (RBG). Other support from The University of Melbourne and Melbourne Water

Corporation (RBG) is gratefully acknowledged.

\section{Availability of data and materials}

Accession codes: Nucleotide sequence data reported in this article are publicly available in the GenBank database under accession nos. MF196907MF196910.

Authors' contributions

TW and RBG planned the study. YF and TW undertook the laboratory work. TW, RBG and YF wrote the manuscript with inputs from AVK and MH. RBG raised the funds for the project. All authors read and approved the final manuscript.

Ethics approval and consent to participate

Not applicable.

Consent for publication

Not applicable.

Competing interests

The authors declare that they have no competing interests.

\section{Publisher's Note}

Springer Nature remains neutral with regard to jurisdictional claims in published maps and institutional affiliations.

Received: 17 September 2017 Accepted: 9 October 2017

Published online: 25 October 2017

\section{References}

1. Ryan U, Fayer R, Xiao L. Cryptosporidium species in humans and animals: current understanding and research needs. Parasitology. 2014;141(13):1667-85.

2. Thompson RC, Ash A. Molecular epidemiology of Giardia and Cryptosporidium infections. Infect Genet Evol. 2016;40:315-23.

3. Ryan U, Caccio SM. Zoonotic potential of Giardia. Int J Parasitol. 2013; 43(12-13):943-56

4. Xiao L. Molecular epidemiology of cryptosporidiosis: an update. Exp Parasitol. 2010;124(1):80-9.

5. Morgan-Ryan UM, Fall A, Ward LA, Hiijawi N, Sulaiman I, Fayer R, et al. Cryptosporidium hominis n. sp. (Apicomplexa: Cryptosporidiidae) from Homo sapiens. J Eukaryot Microbiol. 2002;49(6):433-40.

6. O'Handley RM, Olson ME, Fraser D, Adams P, Thompson RC. Prevalence and genotypic characterisation of Giardia in dairy calves from Western Australia and western Canada. Vet Parasitol. 2000;90(3):193-200.

7. Ortega-Pierres G, Smith HV, Caccio SM, Thompson RC. New tools provide further insights into Giardia and Cryptosporidium biology. Trends Parasitol. 2009;25(9):410-6.

8. Feng Y, Xiao L. Zoonotic potential and molecular epidemiology of Giardia species and giardiasis. Clin Microbiol Rev. 2011;24(1):110-40.

9. Feng Y, Ortega Y, He G, Das P, Xu M, Zhang X, et al. Wide geographic distribution of Cryptosporidium bovis and the deer-like genotype in bovines. Vet Parasitol. 2007;144(1-2):1-9.

10. Ng J, Yang R, McCarthy S, Gordon C, Hijjawi N, Ryan U. Molecular characterization of Cryptosporidium and Giardia in pre-weaned calves in Western Australia and new South Wales. Vet Parasitol. 2011;176(2-3):145-50.

11. Jex AR, Gasser RB. Genetic richness and diversity in Cryptosporidium hominis and C. parvum reveals major knowledge gaps and a need for the application of "next generation" technologies - research review. Biotechnol Adv. 2010;28(1):17-26.

12. Abeywardena H, Jex AR, Gasser RBA. Perspective on Cryptosporidium and Giardia, with an emphasis on bovines and recent epidemiological findings. Adv Parasitol. 2015;88:243-301. 
13. Qi M, Wang H, Jing B, Wang D, Wang R, Zhang L. Occurrence and molecular identification of Cryptosporidium spp. in dairy calves in Xinjiang, northwestern China. Vet Parasitol. 2015;212(3-4):404-7.

14. Snel SJ, Baker MG, Kamalesh V, French N, Learmonth JA. Tale of two parasites: the comparative epidemiology of cryptosporidiosis and giardiasis. Epidemiol Infect. 2009;137(11):1641-50.

15. Cui Z, Wang R, Huang J, Wang H, Zhao J, Luo N, et al. Cryptosporidiosis caused by Cryptosporidium parvum subtype IIA15G1 at a dairy farm in northwestern China. Parasit Vectors. 2014;7:529.

16. Huang J, Yue D, Qi M, Wang R, Zhao J, Li J, et al. Prevalence and molecular characterization of Cryptosporidium spp. and Giardia duodenalis in dairy cattle in Ningxia, northwestern China. BMC Vet Res. 2014;10:292.

17. Li F, Wang H, Zhang Z, Li J, Wang C, Zhao J, et al. Prevalence and molecular characterization of Cryptosporidium spp. and Giardia duodenalis in dairy cattle in Beijing, China. Vet Parasitol. 2016;219:61-5.

18. Liu A, Wang R, Li Y, Zhang L, Shu J, Zhang W, et al. Prevalence and distribution of Cryptosporidium spp. in dairy cattle in Heilongjiang Province, China. Parasitol Res. 2009;105(3):797-802.

19. Qi MZ, Fang YQ, Wang XT, Zhang LX, Wang RJ, Du SZ, et al. Molecular characterization of Cryptosporidium spp. in pre-weaned calves in Shaanxi Province, north-western China. J Med Microbiol. 2015;64(1):111-6.

20. Wang R, Ma G, Zhao J, Lu Q, Wang H, Zhang L, et al. Cryptosporidium andersoni is the predominant species in post-weaned and adult dairy cattle in China. Parasitol Int. 2011;60(1):1-4.

21. Wang R, Wang H, Sun Y, Zhang L, Jian F, Qi M, et al. Characteristics of Cryptosporidium transmission in preweaned dairy cattle in Henan, China. J Clin Microbiol. 2011;49(3):1077-82.

22. Zhang W, Wang R, Yang F, Zhang L, Cao J, Zhang X, et al. Distribution and genetic characterizations of Cryptosporidium spp. in pre-weaned dairy calves in northeastern China's Heilongjiang Province. PLoS One. 2013;8(1):e54857.

23. Liu G, Su Y, Zhou M, Zhao J, Zhang T, Ahmad W, et al. Prevalence and molecular characterization of Giardia duodenalis isolates from dairy cattle in northeast China. Exp Parasitol. 2015;154:20-4.

24. Wang H, Zhao G, Chen G, Jian F, Zhang S, Feng C, et al. Multilocus genotyping of Giardia duodenalis in dairy cattle in Henan, China. PLoS One. 2014;9(6):e100453.

25. Wang XT, Wang RJ, Ren GJ, ZQ Y, Zhang LX, Zhang SY, et al. Multilocus genotyping of Giardia duodenalis and Enterocytozoon bieneusi in dairy and native beef (Qinchuan) calves in Shaanxi province, northwestern China. Parasitol Res. 2016;115(3):1355-61.

26. Wang $X$, Cai M, Jiang W, Wang Y, Jin Y, Li N, et al. High genetic diversity of Giardia duodenalis assemblage E in pre-weaned dairy calves in Shanghai, China, revealed by multilocus genotyping. Parasitol Res. 2017;116(8):2101-10.

27. Wang T, Fan Y, Koehler AV, Ma G, Li T, Hu M, Gasser RB. First survey of Cryptosporidium, Giardia and Enterocytozoon in diarrhoeic children from Wuhan, China. Infect Genet Evol. 2017;51:127-31.

28. Mi R, Wang X, Huang Y, Zhou P, Liu Y, Chen Y, Chen J, Zhu W, Chen Z. Prevalence and molecular characterization of Cryptosporidium in goats across four provincial level areas in China. PLoS One. 2014;9(10):e111164.

29. Nolan MJ, Jex AR, Koehler AV, Haydon SR, Stevens MA, Gasser RB. Molecularbased investigation of Cryptosporidium and Giardia from animals in water catchments in southeastern Australia. Water Res. 2013;47(5):1726-40.

30. Pontiroli A, Travis ER, Sweeney FP, Porter D, Gaze WH, Mason S, et al. Pathogen quantitation in complex matrices: a multi-operator comparison of DNA extraction methods with a novel assessment of PCR inhibition. PLoS One. 2011;6(3):e17916

31. Kosch TA, Summers K. Techniques for minimizing the effects of PCR inhibitors in the chytridiomycosis assay. Mol Ecol Resour. 2013;13(2):230-6.

32. Koehler AV, Korhonen PK, Hall RS, Young ND, Wang T, Haydon SR, et al. Use of a bioinformatics-assisted primer design strategy to establish a new nested PCR-based method for Cryptosporidium. Parasit Vectors. 2017 (In press).

33. Ryan U, Xiao L, Read C, Zhou L, Lal AA, Pavlasek I. Identification of novel Cryptosporidium genotypes from the Czech Republic. Appl Environ Microbiol. 2003:69(7):4302-7.

34. Hopkins RM, Meloni BP, Groth DM, Wetherall JD, Reynoldson JA, Thompson $\mathrm{RC}$, Ribosomal RNA. Sequencing reveals differences between the genotypes of Giardia isolates recovered from humans and dogs living in the same locality. J Parasitol. 1997:83(1):44-51.

35. Appelbee AJ, Frederick LM, Heitman TL, Olson ME. Prevalence and genotyping of Giardia duodenalis from beef calves in Alberta, Canada. Vet Parasitol. 2003;112(4):289-94.
36. Li P, Cai J, Cai M, Wu W, Li C, Lei M, et al. Distribution of Cryptosporidium species in Tibetan sheep and yaks in Qinghai, China. Vet Parasitol. 2016;215:58-62.

37. Zhang XX, Tan QD, Zhou DH, Ni XT, Liu GX, Yang YC, et al. Prevalence and molecular characterization of Cryptosporidium spp. in dairy cattle, northwest China. Parasitol Res. 2015;114(7):2781-7.

38. Gong C, Cao XF, Deng L, Li W, Huang XM, Lan JC, et al. Epidemiology of Cryptosporidium infection in cattle in China: a review. Parasite. 2017;24:1.

39. de Graaf DC, Vanopdenbosch E, Ortega-Mora LM, Abbassi H, Peeters JEA. Review of the importance of cryptosporidiosis in farm animals. Int J Parasitol. 1999;29(8):1269-87.

40. Holland RE. Some infectious causes of diarrhea in young farm animals. Clin Microbiol Rev. 1990;3(4):345-75.

41. Chen YM, Li GD, ZB D, Ma JW, Liu W. Detection of Cryptosporidium in calves in Lanzhou. Chinese J Vet Sci. 1986;12(12):41-2.

42. Ma J, Cai J, Ma J, Feng $Y$, Xiao L. Occurrence and molecular characterization of Cryptosporidium spp. in yaks (Bos grunniens) in China. Vet Parasitol. 2014; 202(3-4):113-8.

43. Chen F, Qiu H. Identification and characterization of a Chinese isolate of Cryptosporidium serpentis from dairy cattle. Parasitol Res. 2012;111(4):1785-91.

44. Ma J, Li P, Zhao X, Xu H, Wu W, Wang Y, et al. Occurrence and molecular characterization of Cryptosporidium spp. and Enterocytozoon bieneusi in dairy cattle, beef cattle and water buffaloes in China. Vet Parasitol. 2015;207(3-4):220-7.

45. Nolan MJ, Jex AR, Mansell PD, Browning GF, Gasser RB. Genetic characterization of Cryptosporidium parvum from calves by mutation scanning and targeted sequencing - zoonotic implications. Electrophoresis. 2009;30(15):2640-7.

46. Geurden T, Berkvens D, Martens C, Casaert S, Vercruysse J, Claerebout E. Molecular epidemiology with subtype analysis of Cryptosporidium in calves in Belgium. Parasitology. 2007;134(14):1981-7.

47. Karanis P, Eiji T, Palomino L, Boonrod K, Plutzer J, Ongerth J, et al. First description of Cryptosporidium bovis in Japan and diagnosis and genotyping of Cryptosporidium spp. in diarrheic pre-weaned calves in Hokkaido. Vet Parasitol. 2010;169(3-4):387-90

48. Santín M, Trout JM, Xiao L, Zhou L, Greiner E, Fayer R. Prevalence and agerelated variation of Cryptosporidium species and genotypes in dairy calves. Vet Parasitol. 2004:122(2):103-17.

49. Cai M, Guo Y, Pan B, Li N, Wang X, Tang C, et al. Longitudinal monitoring of Cryptosporidium species in pre-weaned dairy calves on five farms in Shanghai, China. Vet Parasitol. 2017;241:14-9.

50. Fayer R, Santín M, Xiao L. Cryptosporidium bovis n. sp. (Apicomplexa: Cryptosporidiidae) in cattle (Bos taurus). J Parasitol. 2005;91(3):624-9.

51. Fayer R, Santín M, Trout JM. Cryptosporidium ryanae n. sp. (Apicomplexa: Cryptosporidiidae) in cattle (Bos taurus). Vet Parasitol. 2008;156(3-4):191-8.

52. Esteban E, Anderson BC. Cryptosporidium muris: prevalence, persistency, and detrimental effect on milk production in a drylot dairy. J Dairy Sci. 1995; 78(5):1068-72.

53. Ralston BJ, Cockwill CL, Guselle NJ, Van Herk FH, McAllister TA. Prevalence of Giardia and Cryptosporidium andersoni and their effects on performance in feedlot beef cattle. Can J Anim Sci. 2003:83:153-9.

54. Anderson BC. Abomasal cryptosporidiosis in cattle. Vet Pathol. 1987;24(3): 235-8.

55. Qi M, Wang $H$, Jing B, Wang $R$, Jian F, Ning $C$, et al. Prevalence and multilocus genotyping of Giardia duodenalis in dairy calves in Xinjiang, northwestern China. Parasit Vectors. 2016;9(1):546.

56. Liu A, Yang F, Shen Y, Zhang W, Wang R, Zhao W, et al. Genetic analysis of the Gdh and Bg genes of animal-derived Giardia duodenalis isolates in northeastern China and evaluation of zoonotic transmission potential. PLoS One. 2014;9(4):e95291.

57. Santín M, Dargatz D, Fayer R. Prevalence of Giardia duodenalis assemblages in weaned cattle on cow-calf operations in the United States. Vet Parasitol. 2012;183(3-4):231-6

58. Trout JM, Santin M, Greiner E, Fayer R. Prevalence of Giardia duodenalis genotypes in pre-weaned dairy calves. Vet Parasitol. 2004;124(3-4):179-86.

59. Zhao GH, SZ D, Wang HB, XF H, Deng MJ, SK Y, et al. First report of zoonotic Cryptosporidium spp., Giardia intestinalis and Enterocytozoon bieneusi in golden takins (Budorcas taxicolor bedfordi). Infect Genet Evol. 2015;34:394-401.

60. Becher KA, Robertson ID, Fraser DM, Palmer DG, Thompson RC. Molecular epidemiology of Giardia and Cryptosporidium infections in dairy calves originating from three sources in Western Australia. Vet Parasitol. 2004; 123(1-2):1-9. 
61. Zahedi A, Field D, Ryan U. Molecular typing of Giardia duodenalis in humans in Queensland - first report of assemblage E. Parasitology. 2017;144(9):1154-61.

62. Fantinatti M, Bello AR, Fernandes O, Da-Cruz AM. Identification of Giardia lamblia assemblage $\mathrm{E}$ in humans points to a new anthropozoonotic cycle. $J$ Infect Dis. 2016;214:1256-9.

63. Abdel-Moein KA, Saeed H. The zoonotic potential of Giardia intestinalis assemblage E in rural settings. Parasitol Res. 2016;115(8):3197-202.

64. Helmy YA, Klotz C, Wilking H, Krücken J, Nöckler K, Von SamsonHimmelstjerna G, Zessin KH, Aebischer T. Epidemiology of Giardia duodenalis infection in ruminant livestock and children in the Ismailia province of Egypt: insights by genetic characterization. Parasit Vectors. 2014;7:321.

65. Foronda P, Bargues MD, Abreu-Acosta N, Periago MV, Valero MA, Valladares B, Mas-Coma S. Identification of genotypes of Giardia intestinalis of human isolates in Egypt. Parasitol Res. 2008;103(5):1177-81.

Submit your next manuscript to BioMed Central and we will help you at every step:

- We accept pre-submission inquiries

- Our selector tool helps you to find the most relevant journal

- We provide round the clock customer support

- Convenient online submission

- Thorough peer review

- Inclusion in PubMed and all major indexing services

- Maximum visibility for your research

Submit your manuscript at www.biomedcentral.com/submit
Biomed Central 